\title{
Construct and Criterion-Related Validation of a Measure of Emotional Reasoning Skills: A two-study investigation
}

\section{Gerhard Blickle*, Tassilo S. Momm*, Jochen Kramer*, Jan Mierke*, Yongmei Liu** and Gerald R. Ferris****}

*University of Bonn, Bonn, Germany. gerhard.blickle@uni-bonn.de

** University of Texas at Arlington, Arlington, TX, USA

***Florida State University, Tallahassee, FL, USA

In a two-study investigation, the construct and criterion-related validities of the Test of Emotional Intelligence, an ability-based measure of emotional reasoning skills, were examined. In Study 1, as hypothesized, emotional reasoning skills were related to emotion recognition ability (i.e., as measured by Diagnostic Analysis of Nonverbal Accuracy), emotional empathy, and three measures of successful social functioning (i.e., social astuteness, interpersonal influence, and apparent sincerity) assessed by peers, after controlling for personality and occupational environment characteristics. In Study 2, results from a predictive validation study demonstrated that Emotional Intelligence explained additional variance in overall job performance ratings beyond general mental ability and personality traits. Contributions and implications of this research investigation, limitations, and directions for future research are discussed.

\section{Introduction}

he construct of Emotional Intelligence (EI) has
received a great deal of attention in both popular
books (e.g., Goleman, 1995, 1998) and academic jour-
nals (e.g., Locke, 2005; Mayer, Salovey, \& Caruso, 2004;
Roberts, Zeidner, \& Matthews, 2001). Whereas debates
on various issues of El remain open, both theoretical
and empirical exploration in this area continue to push
El research forward and enrich our understanding of
the scientific properties of El. To date, El has been

The authors wish to express their gratitude to Marcus Bühner, Neal Ashkanasy, and Stéphane Côté for their helpful comments on an earlier version of this paper. examined either as a trait (e.g., Bar-On, 2000), or as an ability (e.g., Daus \& Ashkanasy, 2005; Mayer et al., 2004; Mayer \& Salovey, 1993; Mayer, Salovey, \& Caruso, 2000, 2002; Mayer, Roberts, \& Barsade, 2008). In the current research, we focus on the ability-based model of El.

The ability-based approach to El, originally proposed by Mayer and colleagues (Mayer \& Salovey, 1993, 1997; Mayer et al., 2004), has been widely endorsed among scholars, resulting in considerable empirical research and accumulating evidence regarding the nomological network of El, as well as its criterion-related validity (e.g., Brackett, Rivers, Shiffman, Lerneer, \& Salovey, 2006; Côté \& Miners, 2006; Law, Wong, \& Song, 2004; Lopes, Salovey, \& Straus, 2003; Mayer, Salovey, Caruso, \& Sitarenios, 2003; Rode, Mooney, Artaud-Day, 
Near, Baldwin, Rubin, \& Bommer, 2005; Van Rooy \& Viswesvaran, 2004).

Whereas Mayer and colleagues have taken an integrative-model approach to El (Mayer et al., 2008), which has resulted in the development of the now most widely used ability-based measure, Mayer-Salovey-Caruso Emotional Intelligence scale (i.e., MSCEIT - Mayer et al., 2002; Mayer et al., 2003), others have taken a specificability approach (Mayer et al., 2008) in an effort to unravel particular abilities entailed by individual emotional competencies (e.g., Lane, Quinlan, Schwartz, Walker, \& Zeitlin, 1990; Matsumoto, LeRoux, Wilson-Cohn, Raroque, Kooken, Ekman, Yrizarry, Loewinger, Uchida, Yee, Amo, \& Goh, 2000; Nowicki \& Carton, 1993).

Instead of trying to tackle the global integration of emotional competencies, this research has focused on its specific components, such as the level of emotional awareness (e.g., Lane et al., 1990), the ability to recognize facial expressions of emotions (e.g., Elfenbein, 2006; Elfenbein \& Ambady, 2002; Nowicki \& Carton, 1993), and emotional appraisal and labeling (e.g., Innes-Ker \& Niedenthal, 2002). Whereas developed somewhat independently of the main stream El research, this research has helped move the field forward by providing enhanced understanding about the specific abilities associated with $\mathrm{El}$, as well as the differential utilities in various tasks and contexts. Analyzing specific skills and abilities is also a necessary precondition for successfully training emotional abilities (Elfenbein, 2006). The micro-skills approach to interpersonal skills at work contends that the more specific skills and abilities are identified, the better will be the chance to change them (Hayes, 2002).

The purpose of the present research is to test the construct and criterion-related validities of a newly introduced measure, namely, the Test of Emotional Intelligence (i.e., TEMINT), which takes a specific-ability approach to assess a core element of emotional competency; that is, the ability to reason with emotions. The ability to reason with emotions, or what we call emotional reasoning skills, refers to the ability to employ emotional knowledge to understand and analyze emotions. Specifically, it includes such abilities as being able to understand the links between emotion-eliciting situations and emotional reactions (i.e., emotional appraisal), to accurately label and categorize feelings, and to describe one's own and others' emotional experiences (i.e., emotional understanding) (Mayer et al., 2008; Mayer \& Salovey, 1997). Emotional reasoning skills have been identified as one of the key components of El (Mayer et al., 2004, 2008; Mayer \& Salovey, 1997).

\subsection{Importance of emotional reasoning skills}

Many emotion theorists have argued that emotions are experienced as a result of individuals' appraisals of the person-situation interactions, and different situations elicit different emotions (e.g., Harrison, 1986; Lazarus, 1991; Plutchik, 1980; Scherer, 1984). For example, the experience of sadness is related to an individual's perception of an irrevocable loss; fear is associated with the appraisal of the situation as being dangerous (Smith \& Lazarus, 1993). A person's representations of these associations between situations and elicited emotions sometimes are based on innate mechanisms, whereas others are learned by socialization, observation of others in specific situations, and personal experience (Camras \& Allison, 1989; Denham, 1998; Saarni, 1999).

Appraisal of the events-emotion linkages not only helps individuals understand an event and its consequences, and thereby respond appropriately, but also assists individuals to anticipate, recognize, understand, and respond constructively to others' emotional experiences evoked by situations (Lazarus, 1991). Related to such appraisal is the emotional knowledge that equips individuals with the ability to accurately label and categorize emotional experiences (Clore, Ortony, \& Foss, 1987; Innes-Ker \& Niedenthal, 2002).

Emotional reasoning skills represent valuable emotional competencies, particularly because individuals frequently need to infer others' emotional experiences based on this emotional appraisal process, rather than through observing their emotional expressions. Emotional expressions do not always correspond with inner feelings (Ekman, Friesen, \& Ancoli, 1980; FernándezDols \& Ruiz-Belda, 1997). Societal and organizational display rules frequently require adults to control the expression of their emotions toward others (Ekman, 1972; Hochschild, 1983). Additionally, facial displays of emotions can be manipulated to serve social communication and impression management purposes (Fridlund, 1991; Goffman, 1959; Kraut \& Johnston, 1979).

Therefore, knowledge about the association between situations and emotions can represent an additional, and very helpful, way to infer the actual emotional states of others, even when target persons do not display their emotions. This awareness of others' emotional states allows individuals to develop an enhanced understanding of others' motives and needs (Lazarus, 1991; Plutchik, 1980), based on which they can foster and maintain supportive relationships with others. Another aspect of the importance of emotional reasoning skills is that a thorough knowledge about emotions helps people to predict emotional reactions of others in various situations. This knowledge helps actors to better manage the emotions of self and others (e.g., Prati, Douglas, Ferris, Ammeter, \& Buckley, 2003).

\subsection{TEMINT}

TEMINT was developed by Schmidt-Atzert and Bühner (2002) to assess the ability of emotional reasoning and 
understanding. It is a performance-based test of El that focuses specifically on emotional reasoning skills. In the scale, situations experienced by various target persons are described, for which test takers are asked to rate the target persons' possible emotional experiences. The situations were derived from a larger pool, from which a smaller set were selected by the authors to ensure a variety of events and emotions experienced, a balance on age and gender of the target persons, as well as a reasonable length of the scale. The target persons were asked to report their actual emotional experiences in a given situation on a scale from 0 (i.e., not at all or very weak) to 2 (strong to very strong), which are used as the correct answers to assess the accuracy of emotional reasoning of the test takers. Based on a pilot test, the authors further removed situations for which the participants unanimously failed to reach consistency with the target person in terms of the emotional experiences.

TEMINT contains a total of twelve situations. An example of the situation is, 'A 30-year-old female computer specialist reports: 'My cat was ill. I had to take him to the surgeon. I thought I had poisoned him with insect spray. How did this person feel in this situation?' The feelings to be rated were dislike, anger, fear, unease, sadness, guilt, happiness, pride, affection, and surprise. The test taker has to rate these feelings experienced by the target persons in each situation. The TEMINT score is calculated as the sum of the absolute differences between a test taker's ratings and the correct estimations of various emotions across situations (i.e., ratings of the target person). As such, lower TEMINT scores indicate higher emotional reasoning skills.

As is evident from the above description, in order to perform well on the test, the test takers have to possess emotional reasoning skills discussed earlier. That is, they must demonstrate the ability to discern the linkage between events and emotions (e.g., sadness often accompanies a loss), to accurately label and categorize emotions with emotion words, and to understand other people's feelings, including complex feelings (i.e., simultaneous experiences of multiple, sometimes conflicting, emotions) evoked by situations.

TEMINT has yielded adequate reliability estimates of .76 (Amelang \& Steinmayr, 2006) and .77 (SchmidtAtzert \& Bühner, 2002), respectively. Schmit-Atzert and Bühner (2002) reported that the TEMINT score was correlated significantly with fluid, numerical, and figural intelligence $(-.24 \leq r \leq-.16)$, and with the personality trait of openness to experience $(r=-.22)$, a variable that relates to many forms of intelligence (Ackerman \& Heggestad, 1997). Amelang and Steinmayr (2006, p. 467) commented that TEMINT is 'a thoughtfully developed and promising measure of Ability El,' which exhibits encouraging evidence for construct validity comparable to that found for MSCEIT (Mayer et al., 2004).

It is the purpose of the present research to extend the validation of TEMINT as a specific-ability measure of EI (i.e., a tool to assess the skill to correctly appraise, label, and understand emotions evoked by situations). Specifically, we conducted two studies to explore the relations of TEMINT to several key benchmarks of an EI measure identified by Mayer et al. (2008). In Study 1, we examine the relationship between TEMINT and another specific ability measure of El that assesses ability to perceive emotions [i.e., DANVA (Diagnostic Analysis of Nonverbal Accuracy) - Nowicki \& Carton, 1993; Baum \& Nowicki, 1998], personality traits of openness to experience, and social functioning (i.e., social astuteness, interpersonal influence, and apparent sincerity) assessed by peers.

In Study 2, we examine the relationship between TEMINT and job performance ratings. The association between El and performance is arguably one of the most provocative ideas in El research (Côté \& Miners, 2006; Caruso \& Salovey, 2004). The idea is appealing to many because it challenges the conventional wisdom that performance is primarily determined by cognitive abilities, and it offers new insights for practioners in performance interventions. Côté and Miners (2006) reported that employees' El was associated with job performance ratings even after controlling for the Big Five personality dimensions and cognitive intelligence. The present research investigates whether this effect holds true for emotional reasoning skills.

\subsection{Correlates of TEMINT}

\subsubsection{Correlation with another EI measure - DANVA}

DANVA is a scale developed by Nowicki and colleagues (Nowicki \& Carton, 1993; Baum \& Nowicki, 1998) to measure the emotion perception ability, which represents branch 1 of the ability model of El. It involves the capacity to identify emotion in one's physical state, feelings, and thoughts, to recognize emotion in others' facial and postural expressions, as well as nonverbal perception and expression of emotion in the face, voice, and related communication channels (Mayer \& Salovey, 1997; Mayer et al., 2004). Emotion perception ability is the most reliably validated facet of ability EI (Elfenbein \& Ambady, 2002), which can be assessed from pictures of faces or body postures. Several studies have indicated that emotion perception in facial expression or pictures has acceptable reliability upon replication (Davies, Stankov, \& Roberts, 1998; Ciarrochi, Chan, \& Caputi, 2000).

Representing perhaps the most basic and fundamental component of the four-branch model of El (Mayer \& Salovey, 1997), emotion perception ability has been 
found to positively correlate with all three other components of El (e.g., Brackett \& Mayer, 2003; Mayer et al., 2003). Therefore, we hypothesized that emotion perception ability, as measured by DANVA, is positively associated with emotional reasoning skills, as measured by TEMINT. Because the DANVA score is also reverse scored, we propose the following:

Hypothesis 1: There is a positive relationship between TEMINT score and the DANVA score.

\subsubsection{Relationship with empathy}

Empathy refers to the reactions of an individual to the observed experiences of others (Eslinger, 1998). Key aspects of empathy include taking the perspective of others, and other-oriented feelings of sympathy and concerns (Davis, 1983), both of which are based on the emotional competencies of recognizing and understanding others' feelings. Thus, empathy has been theorized to be associated with El (Mayer et al., 2008). Consistent with this argument, self-ratings of empathetic feelings have been found to exhibit significant, positive correlations with MSCEIT, and a measure for emotional awareness (i.e., Levels of Emotional Awareness Scale; Lane et al., 1990) (e.g., Brackett et al., 2006; Ciarrochi et al., 2000). Therefore, we hypothesized that self-rating scores of empathy are associated with emotional reasoning skills. Again, because the TEMINT score is reverse scored, we propose the following:

Hypothesis 2: There is a negative relationship between the TEMINT score and self-ratings of empathy.

1.3.3. Relationship with a benchmark personality trait openness to experience

El measures often have been examined in relation to benchmark personality traits, most often the Big Five (Mayer et al., 2008). Over the past couple of decades, personality scholars generally have concluded that a five-factor model most accurately and comprehensively characterizes the nature of normal adult personality (e.g., Goldberg, 1993). The five factors identified are: neuroticism, extraversion, agreeableness, conscientiousness, and openness to experience.

Persons with high scores on the openness to experience scale describe themselves as intellectual, curious, and imaginative (McCrae, 1996). They are motivated to become deeply involved in the fictitious world of characters in books, movies, and plays, as well as to attend to the moods and feelings that different environments produce. Mayer and Salovey (1993) predicted El would have a low but significant relation to openness to experience, which was supported by recent review of El studies (Mayer et al., 2008, p. 519). As mentioned earlier, Schmidt-Atzert and Bühner (2002) also re- ported a significant correlation between TEMINT and openness to experience.

Based on previous research (Mayer et al., 2004) we expect no substantial relationships between TEMINT and the other Big Five dimensions. However, these dimensions will serve as control variables in the present research. Because TEMINT is reverse scored, we propose the following hypothesis:

Hypothesis 3: There is a negative relationship between the TEMINT score and self-rating of openness to experience.

\subsubsection{Relationship to social functioning}

Social interactions frequently are emotion-laden (Weiss \& Cropanzano, 1996). To react to social situations effectively, individuals have to understand emotions of others, as well as the attitudes, behavioral intentions, motives, and needs signaled by those emotions (Lazarus, 1991; Plutchik, 1980). Individuals with emotional reasoning skills are able to go beyond facial expressions, and read into the relational meaning of the emotioneliciting situations (Mayer \& Salovey, 1997). Therefore, they are able to better attend to others' needs, and react to social situations more effectively. Their emotional knowledge and understanding also will make them more successful in social influence attempts, and enhances interpersonal trust (Klein, DeRouin, \& Salas, 2006).

Previous research has shown that ability El is positively related to social functioning. Lopes, Brackett, Nezlek, Schütz, Sellin, and Salovey (2004) found that ability El was positively related to the quality of interactions with friends, evaluated separately by others and two friends. Brackett et al. (2006) found that men's ability El correlated with perceived social competence even when partialing out the Big Five personality traits, empathy, and verbal intelligence. In an additional study, ability El predicted for men real-time social competence in a getting-acquainted meeting with an ostensible stranger. Because TEMINT is reverse scored, we propose the following hypothesis:

Hypothesis 4: There is a negative relationship between the TEMINT score and other-perceived social astuteness, interpersonal influence, and apparent sincerity.

\subsubsection{Relationship to job performance ratings}

Emotional reasoning skills will enhance job performance for at least two reasons. First, individuals with high emotional reasoning skills are able to well understand their own emotional experiences, which will facilitate effective self-regulation of behaviors and thoughts (Mayer \& Salovey, 1997). To the degree individuals are able to appraise situations accurately, they are more likely to experience energizing emotions 
that facilitate task performance (Lazarus, 1991; Weiner, 1985). Second, most jobs exist in a social context, and job performance depends at least in part on individuals' abilities to handle social relationships at work (Klein et al., 2006; Wageman, 2001).

Resources availability to individuals for effective performance on tasks often is a function of friendship and interpersonal rapport (Rogers, 1982). As such, social effectiveness indicators have become increasingly recognized as important in the prediction of job performance in contemporary and future work contexts (Ferris, Perrewé, \& Douglas, 2002; Klein et al., 2006). We expect that emotional reasoning skills will enhance job performance because an accurate appraisal and understanding of others emotions will facilitate relationship building and maintenance (Klein et al., 2006), and therefore, increase an individual's access to resources critical for performance on the job.

Past research has presented evidence for the performance-enhancing effect of both overall El and specific El abilities (e.g., Côté \& Miners, 2006; Elfenbein, Foo, White, Tan, \& Aik, 2007; Lam \& Kirby, 2002; Law et al., 2004). For example, Côté and Miners (2006) showed that El, as measured by MSCEIT (Mayer et al., 2002), predicts task performance after controlling both for personality traits and general mental ability (GMA). Elfenbein et al. (2007) conducted a meta-analysis of 18 studies and concluded that emotion recognition accuracy represents a significant and consistent predictor of individual success in organizational settings. In addition, Elfenbein, Polzer, and Ambady (2007) found that emotion recognition accuracy of members in a team accounted for $28.1 \%$ of the variance in team performance ratings completed by peers nearly a year later. Because the TEMINT score is reverse scored, we propose the following:

Hypothesis 5: There is negative relationship between the TEMINT score and overall job performance after controlling for the effects of GMA and the Big Five personality traits.

\section{Study 1: Method}

\subsection{Participants and procedure}

Study 1 was conducted to test Hypotheses 1 through 5. The study was conducted in Bonn, Germany. Two hundred and thirty-two potential participants were contacted personally by 44 bachelor students in Psychology at the University of Bonn, in partial fulfillment of their study requirements. These students were informed about the importance of obtaining variability in the sample of participants on variables such as gender, age groups, job functions, and occupational types. As such, the sample was recruited with the goal of obtaining a group of individuals with as diverse backgrounds as possible so that variability in $\mathrm{El}$ is optimized. Participants were provided with feedback on their results after the data collection was finished.

The participants were 210 peer assessors and 210 target persons who are active employees. The mean number of weekly work hours of the target persons was $38.26 \mathrm{~h}$ per week $(S D=10.87)$. Their mean years of work experience was 20.9 years $(S D=11.9)$. The mean age of the target persons was 47.2 years $(S D=11.2$, range $=30-71)$. Of the targets, $5 \%$ were unskilled and manual employees, $19 \%$ were clerical workers, technicians, or owners of little businesses, $37 \%$ belonged to the administrative personnel, were minor professionals or owners of medium businesses, $33 \%$ were business managers or professionals, and $3 \%$ were higher executives. Six (3\%) targets gave no information concerning their socio-economic status.

Participants were sampled according to gender ( $50.5 \%$ were male) and age (31\% were between 30 and 39 years, $23 \%$ were between 40 and 49 years, 25\% were between 50 and 59 years, and $20 \%$ were 60 years and older). We chose these age groups because they have been rarely researched in previous studies on $\mathrm{El}$ (Van Rooy \& Viswesvaran, 2004). In addition, participants were sampled according to job function and occupational types. We coded jobs using participants' descriptions of their occupations and work task and a classification system of jobs (Jörin, Stoll, Bergmann, \& Eder, 2004) based on a German adaptation of Holland's (1997) occupational classification.

A total of $52 \%$ were supervisors active in social jobs with at least four persons reporting directly to them, and $48 \%$ were employees from various types of jobs (i.e., $5.7 \%$ realistic, $9 \%$ artistic, $12.4 \%$ investigative, $8.6 \%$ enterprising, and $12.4 \%$ conventional jobs; Holland 1997). We recruited supervisors from social jobs and employees from all six of Holland's job types to avoid range restriction concerning interpersonal job demands. Supervisory functions in social occupations combine social and enterprising job demands. Based on Holland's hexagonal model of job demands (1997), we assumed that interpersonal job demands were highest in social and enterprising jobs, and lowest in realistic and investigative jobs.

Participants were met at their home. The research assistants received extensive training in advance to standardize behavior toward participants. The research assistants explained that it was necessary that the participants be able to work alone and undisturbed for at least $1 \mathrm{~h}$ during the testing. First, the research assistants administered the test of emotion recognition ability (i.e., DANVA). Then, the participants received the other tests in a booklet. Participants worked on these paper-and-pencil tests in the presence of the 
research assistants. Finally, participants received a test booklet in an envelope which they were asked to give to a peer who knew the target participant already for some time and who was ready to assess this target participant anonymously.

In the cover letter the assessors were asked to send their test booklet immediately after having it worked through back to the university in a prepaid envelope. To ensure open and honest other assessments, we did not ask the peers for any personal information so that it was also obvious for them that they could not be identified afterwards but made their ratings completely anonymously. A code was used to link the target person with the peer assessor. Only the research assistants knew the code numbers.

\subsection{Measures}

\subsubsection{Emotional reasoning skills - TEMINT}

As mentioned earlier, 12 situations are described. Respondents have to rate 10 feelings experienced by different target persons in each situation The TEMINT score represents the degree to which participants' responses diverge from the emotions of the original target persons. Based on the 12 situations, SchmidtAtzert and Bühner (2002) reported a Cronbach's $\alpha=.77$. In the present study, Cronbach's $\alpha$ reliability of the scale was .82 .

\subsubsection{DANVA}

DANVA (Nowicki \& Carton, 1993; Baum \& Nowicki, 1998) comprises an Adult Faces and an Adult Paralanguage scale. Each scale contains 24 emotional expressions, using photographs of faces and audiotapes of voices, respectively. In each subtest, there are six items each for the emotion of anger, fear, happiness, and sadness. The DANVA score represents the degree to which participants' responses diverge from the correct emotions. The 48-item scale ranges between 0 and 48 points, with higher score indicating lower nonverbal accuracy.

The DANVA test has been extensively validated (Nowicki \& Duke, 1994, 2001), and used widely in at least 36 published papers, 33 doctoral theses, and 19 master-level theses (cf. Elfenbein \& Ambady, 2002). Criterion validity tests link DANVA scores to social adjustment, discriminant validity tests distinguish between DANVA scores and traditional test of GMA, and convergent validity tests link DANVA to Rosenthal, Hall, DiMatteo, Rogers, and Archer (1979) Profile of Nonverbal Sensitivity test. In the present study, Cronbach's $\alpha$ reliability of the scale was .64 . Additionally, a test-retest reliability study over a period of 4 weeks with a sample of 36 bachelor students in Psychology was conducted. The retest reliability of the scale was $r=.85(p<.005)$.

\subsubsection{Openness to experience}

Openness to experience was measured with the German version of the Neo Five Factor Inventory (NEOFFI) (Borkenau \& Ostendorf, 1993; Costa \& McCrae, 1989). In the present study, Cronbach's $\alpha$ of the 12 -item scale was .77.

\subsubsection{Empathy}

A German translation of Mehrabian and Epstein's (1972) measure of emotional empathy was used in the present study. The 33-item scale treats empathy as the tendency to respond emotionally to the experiences of others. The Likert-type items range between ' 0 - not at all' and ' 5 - complete agreement.' In the present study, Cronbach's $\alpha$ of the scale was .84 .

\subsubsection{Social functioning}

Social functioning was assessed by others with the following three sub-scales from the Political Skill Inventory (PSI) (Ferris, Treadway, Kolodinsky, Hochwarter, Kacmar, Douglas, \& Frink, 2005; Ferris, Davidson, \& Perrewé, 2005). Social astuteness (five items, $\alpha=.67$ ): Persons who are socially astute are sensitive to others (Sample item: 'This person understands people very well.). Interpersonal influence (four items, $\alpha=.83$ ): Persons who are high on interpersonal influence have a profound ability to persuade others, and can adapt this skill to different targets of influence attempts (Sample item: 'This person is able to communicate easily and effectively with others.'). Apparent sincerity (three items, $\alpha=.65$ ): this concerns possessing or appearing to possess authenticity, genuineness, and integrity. Persons high on apparent sincerity are more likely to gain the trust and support of others as they engage in influence attempts (Sample item: 'This person tries to show a genuine interest in other people.'). A German translation of the PSI by Blickle, Meurs, Schneider, Kramer, Zettler, Maschler, Noethen, and Ferris (2008) was used in the present study. The three scales used a seven-point Likert-type response scale. Recent research has reported significant correlations of employee self-reports of these scales with subordinate reports, peer reports and supervisor reports (Ferris, Blickle, Schneider, Kramer, Zettler, Solga, Noethen, \& Meurs, 2008; Liu, 2006).

\subsection{Control variables}

In the prediction of the assessment of social functioning by TEMINT, we controlled for gender and age, for job function (i.e., supervisor vs employee), for the other four personality traits in the Big Five (measured by 
NEO-FFI; Borkenau \& Ostendorf, 1993; Costa \& McCrae, 1989), and for the occupational environment characteristics (Holland, 1997) in a regression analyses to rule out any alternative explanation.

The Umwelt-Struktur-Test: Environmental-Structure-Test (Bergmann \& Eder, 1992) was used to measure Holland's (1997) six occupational environment characteristics (R-I-A-S-E-C). We used two items of the test for each job type. The importance of 12 job features were rated $(5=$ very important; $1=$ not important). Sample items are: 'Working with machines or technical instruments' (realistic environment), 'researching the causes of a problem' (investigative environment), 'to design something artistically' (artistic environment), 'Tutoring or curing other people' (social environment), 'Leading a group of people while at work' (enterprising environment), and 'checking accounts' (conventional environment). The occupational environment features were assessed by the target participants. In the present study, Cronbach's $\alpha$ of the scales were: Realistic: .78, Investigative: .70, Artistic: .86, Social: .69, Enterprising: .56, Conventional: .50.

\subsection{Data analyses}

We tested Hypotheses $1-4$ by using correlation analyses, and Hypothesis 5 was tested with regression analyses (Aiken \& West, 1991). The three measures of successful social functioning (i.e., social astuteness, interpersonal influence, and apparent sincerity) assessed by others were regressed on gender, age, job function, the personality traits, the psychological job types, and emotional reasoning skills (i.e., TEMINT score).

\section{Study 1: Results}

Table 1 reports the means, standard deviations, intercorrelations, and coefficient $\alpha$ reliability estimates of all variables in Study 1. In line with Amelang and Steinmayr (2006), we found no gender effect for TEMINT. Additionally, consistent with Schmidt-Atzert and Bühner (2002), we found no significant correlation between age and TEMINT. As expected, TEMINT was significantly related to job function and job type. Because we sampled supervisors active in social jobs, the enterprising and the social job types were mixed. Supervisors in social jobs scored lower (i.e., were more accurate) on TEMINT than employees, and persons in social jobs scored lower (i.e., were more accurate) on TEMINT than in conventional, realistic, and investigative job types.

Based on Hypothesis 1, we expected a positive relationship between emotion perception ability (i.e., measured by DANVA) and emotional reasoning skills (i.e., measured by TEMINT). As Table 1 shows, these variables correlated positively (i.e., $r=.26, p<.05$ ), which confirmed Hypothesis 1 . Hypothesis 2 proposed a negative relationship between self-ratings of empathy and emotional reasoning skills. As Table 1 shows, the empathy scale and the TEMINT score correlated negatively (i.e., $r=-.26, p<.05$ ), thus supporting Hypothesis 2.

Hypothesis 3 proposed a negative relationship between self-ratings of openness to experience and emotional reasoning skills. As Table 1 shows, the openness to experience scale and the TEMINT score correlated negatively $(r=-.21, p<.05)$. In addition, this is the strongest relationship with all of the personality variables. Thus, the data are in line with previous findings by Schmidt-Atzert and Bühner (2002), and support Hypothesis 3.

As Table 1 also shows, all three social functioning variables (i.e., social astuteness, interpersonal influence, and apparent sincerity), as assessed by peers from the social environment of the target persons, correlated negatively with TEMINT, which is in line with Hypothesis 4. Table 2 reports the regressions of social astuteness, interpersonal influence, and apparent sincerity as assessed by peers on gender, age, job function, personality traits, the psychological job types, and emotional reasoning skills (i.e., TEMINT) to test Hypothesis 4.

Based on Hypothesis 4, we expected a negative relationship between emotional reasoning skills and social astuteness, interpersonal influence, and apparent sincerity. These expectations were overall confirmed. The TEMINT scores explained a significant portion of variance in the social astuteness variable and the apparent sincerity variable, even after controlling for personality and job types variables. However, the relationship between TEMINT and the interpersonal influence variables was somewhat weaker, albeit still statistically significant at conventional levels $(p<.05)$. This may be due to the presence of two other substantial predictors; namely, extraversion and openness to experience.

\section{Study 2: Method}

\subsection{Participants and procedure}

Study 2 was conducted to test Hypothesis 5 . Hypothesis 3 was tested again in this study as well. This study also was conducted in Bonn, Germany. Target participants of the study were contacted through advertisements in local newspapers and magazines. The advertisements stated that the researchers were looking for participants for a study on intelligence. Participants were offered and received individual feedback on 


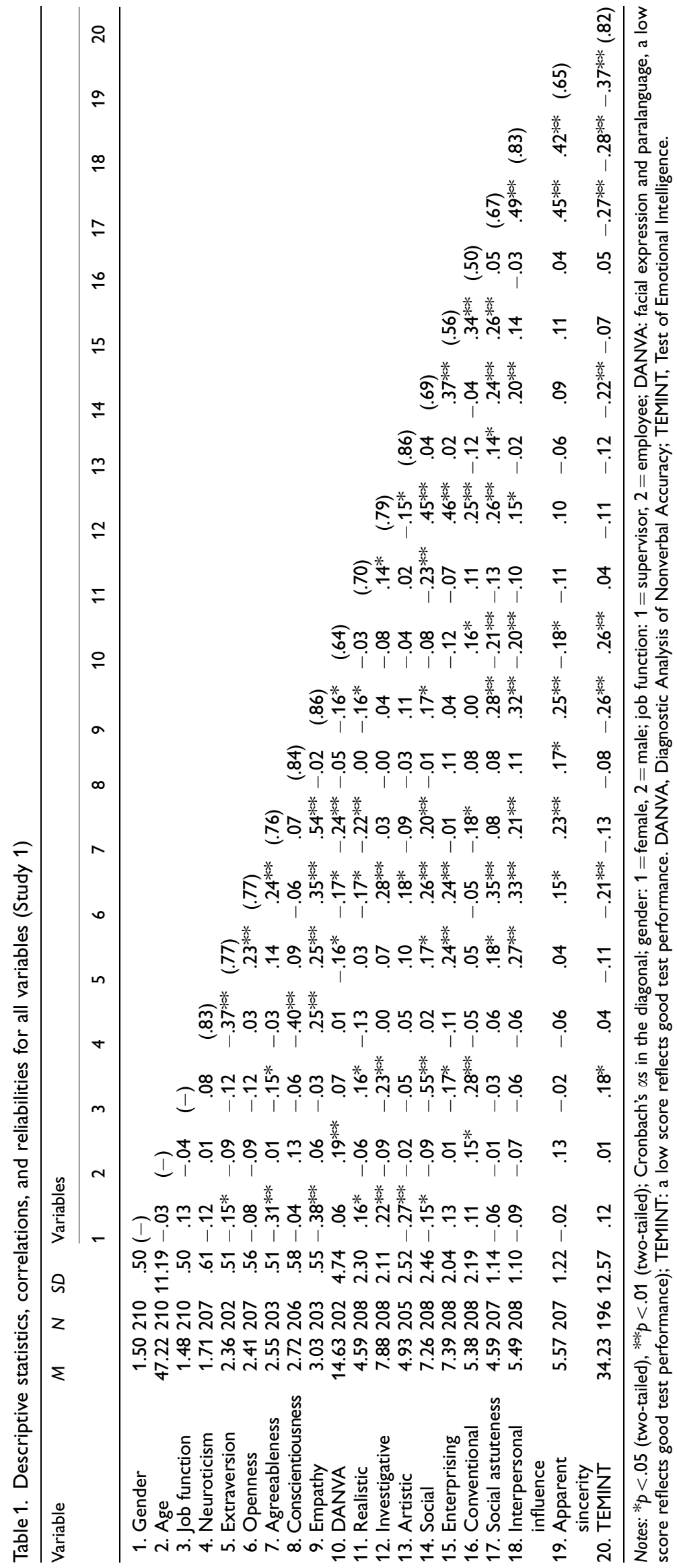


Table 2. Regressions of social functioning assessments by peers on TEMINT (Study 1)

\begin{tabular}{lllc}
\hline Predictors & $\begin{array}{l}\text { Social } \\
\text { astuteness } \\
\text { assessed } \\
\text { by peers } \\
\text { Std. } \beta \mathrm{s}\end{array}$ & $\begin{array}{l}\text { Interpersonal } \\
\text { influence } \\
\text { assessed } \\
\text { by peers } \\
\text { Std. } \beta \mathrm{s}\end{array}$ & $\begin{array}{l}\text { Apparent } \\
\text { sincerity } \\
\text { assessed } \\
\text { by peers } \\
\text { Std. } \beta \mathrm{s}\end{array}$ \\
\hline Targets' gender & -.02 & -.05 & .03 \\
Targets' age & .04 & -.01 & .11 \\
Targets' job function & $.16^{+}$ & .10 & .06 \\
Neuroticism & .10 & .01 & .02 \\
Extraversion & $.15^{+}$ & $.22^{*}$ & .02 \\
Openness & .14 & $.20^{*}$ & .01 \\
Agreeableness & -.11 & -.02 & $.14^{+}$ \\
Conscientiousness & .02 & .02 & .07 \\
Realistic & -.11 & -.05 & -.06 \\
Investigative & $.29 * * *$ & .08 & .05 \\
Artistic & .08 & -.10 & -.08 \\
Social & .05 & .11 & -.02 \\
Enterprising & .09 & .00 & .06 \\
Conventional & -.04 & -.06 & .05 \\
TEMINT & $-.19 *$ & $-.15^{+}$ & $-.31^{* * *}$ \\
$R^{2}$ adjusted & $.19 * * *$ & $.12^{* * *}$ & $11^{* * *}$ \\
\hline
\end{tabular}

Notes: $N=$ dyads of 196 target and assessors. ${ }^{+} p<.05$ (one-tailed), ${ }^{*} p<.05$ (two-tailed), ${ }^{* * *} p<.005$ (two-tailed). TEMINT, Test of Emotional Intelligence.

their performance on the intelligence test. Participants had to be currently active in the working world for at least $12 \mathrm{~h}$ a week. Data were collected for 210 target participants $(71.4 \%$ female, $28.6 \%$ male) whose age ranged between 21 and 63, with a mean age of 42.40 . Most of them were active in conventional, social, or enterprising jobs, or a combination of these three types of jobs (Holland, 1997).

The research design was predictive and longitudinal in nature. Wave one data collection was comprised of the TEMINT emotional reasoning skills measure and intelligence testing procedures. Two months later, participants were sent three parallel other-assessment questionnaires of target individuals' job performance and prepaid return envelopes. The questionnaires were to be completed by a supervisor, a peer, and a subordinate of the target participants. Because of the considerable variety in organizational structure of participants' job environments, other combinations and relevant rating sources were welcomed as well, including customers or other (peer) owners of businesses with whom participants were in close contact. These raters were recruited by the target participants. Three months later, target participants received a package in the mail with the Big Five personality questionnaires.

\subsection{Measures}

\subsubsection{GMA}

GMA was measured using the German version of the 50-item, 12-min Wonderlic Personnel Test (WPT;
Wonderlic, 1996). The WPT is a speed measure that assesses vocabulary, arithmetic reasoning, and spatial abilities, and it is widely used for personnel selection in the United States. Participants were randomly assigned to one of two groups. In group $A$, the intelligence test was administered in small groups $(n \approx 6)$ at the university campus. In group $B$, the same test was administered in the course of a telephone interview. To prevent cheating before and during telephone testing in group $B$, we followed a procedure that has been previously applied successfully by other researchers (Kent \& Plomin, 1987; Kliegel, Martin, \& Jäger, 2007; Legree, Fischl, Gade, \& Wilson, 1998).

Test packets were mailed to the participants in sealed envelopes, with the written instructions that the seal should not be broken until testing commenced. Before beginning the testing, the research assistants were speaking to the participants over the phone, and asked whether the participants would be able to work without disturbance or interruption during the next hour, and whether the participants were alone. If the research assistants heard additional voices, they asked the participants to send the other person out of the room. The research assistants then asked the participants to break the seal and open the tests. Research assistants were able to hear the breaking of the seal. Testers reported no suspicions of incidents of cheating.

The GMA scores were normally distributed (Kolmogorov-Smirov Z-test) in both groups. The means of the scores in the two randomized groups differed significantly $(p<.05$; group $A: M=31.72, S D=6.03$; group $B$ : $M=28.62, S D=5.44)$. Therefore, in order to statistically control for the potential effects of face-to-face vs phone assessment of GMA, the group membership of the targets was coded, and used in the hierarchical regression analysis as a control.

\subsubsection{Emotional reasoning skills}

As in Study 1, TEMINT was used to measure emotional reasoning skills. The means of the TEMINT scores did not differ significantly in the two randomized groups (telephone assessment; $M=32.04, S D=9.45$; face-toface assessment: $M=32.21, S D=9.62$ ).

\subsubsection{Openness to experience}

Openness to experience was measured with the same German version of the NEO-FFI (Borkenau \& Ostendorf, 1993; Costa \& McCrae, 1989) as was used in Study 1 . In the present study, Cronbach's $\alpha$ of the 12item scale was .63 .

\subsubsection{Job performance ratings}

Job performance ratings were assessed with an overall job performance measure from Blickle et al. (2008). To assure content validity, following Schmitt, Cortina, Ingerick and Wiechmann (2003), the scale taps task 
performance, contextual performance, and adaptive performance, with two items for each performance dimension. In addition, contextual performance separates into two dimensions (e.g., Conway, 1999; Van Scotter \& Motowidlo, 1996); namely, interpersonal facilitation and job dedication.

The performance scales are comprised of the following items: '1. How fast does this person usually complete her tasks?; 2. How is the quality of this person's performance altogether?; 3. How successful is this person in dealing with unforeseen and/or unexpected events (disturbances, interruptions, losses/deficiencies, crises, stagnations) in her job activity generally?; 4. How well does this person adjust herself to changes and innovations?; 5 . How sociable does this person act in co-operation with others?; 6 . How reliably does this person meet work-related commitments and agreements?' Items 1 and 2 represent important aspects of task performance, items 3 and 4 represent important aspects of adaptive performance, item 5 represents interpersonal facilitation, and item 6 represents job dedication.

The scale was designed to sample performance ratings from jobs in varying (e.g., social, enterprising, and conventional) domains. Therefore, the performance ratings are carried out in reference to persons in comparable positions. The rating anchors ranged from 'a great deal better than other persons in a comparable position' to 'much worse than other persons in a comparable position,' with 'better than,' 'as good as,' and 'worse than' as intermediate anchors. For each item, raters also had the opportunity to choose the option, 'can't say.'

Because job performance demands typically differ within the same domain from job to job, the importance of each performance facet also was directly assessed by the raters. The rating anchors are 'very important in this job,' 'important in this job,' 'less important in this job,' and 'not important in this job,' as intermediate anchors, as well as the answer option 'don't know.' The rating of how well a job incumbent performs in a given domain is weighted by the importance rating of the respective aspect ranging from 0 (irrelevant) to 1 (highly relevant). 'Don't know' responses were coded as missing.

To improve reliability and validity (De Gruijter, 2003), job performance ratings were sampled from supervisors, peers, subordinates, and others (e.g., customers, clients, etc.) available for a particular target participant. However, complete ratings for all sources were not returned for all participants. In some instances, we obtained only one other-rating, sometimes we got two other-ratings, and sometimes we received three other-ratings. Furthermore, the other-ratings had mixed combinations of kinds of raters: peer-supervisor, supervisor-supervisor, peer-subordinate, supervisor- subordinate, supervisor-peer-peer, etc. Thus, the performance ratings were aggregated across all supervisor-, peer-, subordinate-, and other-ratings available for a particular target participant. The weighting was done at the level of each rater. Subsequently, the weighted ratings were averaged for each target. The scale achieved an acceptable level of internal consistency reliability (i.e., Cronbach's $\alpha=.80$ in Blickle et al., 2008).

In the interest of parsimony, we investigated the extent to which the job performance rating scale assessed a general factor of overall job performance (Viswesvaran, Schmidt, \& Ones, 2005). Blickle et al. (2008) tested the fit of a one-factor model of job performance in a sample of 326 participants. The confirmatory factor analysis starting from a covariance matrix and, using maximum likelihood estimates, reported the following fit indices $(\mathrm{GFI}=.962$; AGFI $=.912, \mathrm{NFI}=.924, \mathrm{NNFI}=.900, \mathrm{CFI}=.940, \mathrm{RMR}=$ .004$, SRMR $=.044)$. Spector $(2001)$ summarized the criteria of good fit for the different index types. According to these criteria, the general factor model of overall job performance in the validation study reflects a good overall fit.

To further validate the job performance scale, a separate study was conducted, with an independent sample of 79 employees, whose performance was assessed each by two supervisors. Cronbach's $\alpha$ reliability in one group of supervisors was $\alpha=.82$ and in the other group $\alpha=.83$. The interrater agreement between the supervisors assessing the same target was $r=.53$ $(p<.01)$. The present overall job performance scale and the overall performance scale reported by Ferris, Witt, and Hochwarter (2001) (i.e., comprising task performance, job dedication, and interpersonal facilitation) demonstrated a strong and significant relationship (i.e., $r=.75, p<.01)$. These findings additionally support the reliability and validity of the present overall job performance ratings scale.

\subsection{Control variables}

Previous research has shown gender (i.e., Bowen, Swim, \& Jacobs, 2000) and age (i.e., Waldman \& Avolio, 1986) to demonstrate an impact on performance ratings. Therefore, gender and age served as control variables in the analyses. To control for the potential effects of face-to-face vs phone assessment of GMA, the targets's assessment group was coded. As noted by Ferris et al. (2001), it is critical to ensure that the contributions of social effectiveness constructs to the prediction of job performance are not due to the effects of personality. Therefore, as done in prior research (i.e., Ferris et al., 2001), we also controlled for the NEO-FFI personality constructs. 
Previous research has suggested that the quality of judgmental validation criteria varies depending on the opportunity for the rater to observe ratees' job performance (Harris \& Schaubroeck, 1988). We operationalized the opportunity for the raters to observe ratees' job performance with three variables, including the time of collaboration (in months) between the assessor and the target person, the contact frequency between assessor and target (ranging from 'several times a day' to 'at least once in a month'), and the interrelatedness between the work of the assessor and that of the target person (ranging from 'very strong' to 'no interrelatedness'). The greater the time that the rater and the target have collaborated, the more frequently they are in contact with one another, and the more interrelated their work, the better the opportunity for the rater to observe the ratee's job performance.

Previous research also has shown rater's liking of the ratee (e.g., Ferris, Judge, Rowland, \& Fitzgibbons, 1994; Judge \& Ferris, 1993) to demonstrate an impact on performance ratings. Therefore, the personal relations (from very close to formal) between the rater and the ratee also served as control variables in the analyses. In addition, Harris and Schaubroeck (1988) reported research that raters at different organizational levels may define and measure performance differently, and may weight performance dimensions differently. Harris and Schaubroeck found a large proportion of unexplained variance concerning the supervisor-peer rating agreement of targets' performance. Therefore, the proportion of supervisors out of the total number of assessors also was controlled. For instance, if a person was assessed by one supervisor, one peer, and one subordinate, this supervisor proportion was .33. All relationship variables were assessed by the performance raters.

\subsection{Data analyses}

Hypothesis 5 was tested in Study 2 using hierarchical regression analysis. The measure of overall job performance assessed by supervisors, peers, and others (i.e., employees, customer, clients) was regressed on gender, age, GMA, personality traits, relationship variables, and emotional reasoning skills (i.e., TEMINT score).

\section{Study 2: Results}

Table 3 reports the means, standard deviations, correlations, and coefficient $\alpha$ reliability estimates of all variables in Study 2. Table 3 also includes in the last three rows the performance ratings given by supervisors, peers, and subordinates separately. While the directions of these different performance assessments were similar, however, the numbers of targets assessed by these different rater groups varied substantially. Therefore, it appears that the aggregation of the different raters per each target is sensible. Thus, aggregated ratings of job performance are used in further analysis.

TEMINT and GMA were uncorrelated. With the exception of openness to experience, the personality scales demonstrated respectable reliabilities. Contrary to Study 1, TEMINT and openness to experience were not correlated. Thus, Hypothesis 3 failed to be supported in Study 2. As expected, the assessments of overall job performance by supervisors, peers, and others correlated significantly with TEMINT $(r=-.24$, $p<.05)$ and the conscientiousness scale $(r=.22$, $p<.05)$ in the expected directions. Like some other previous studies (Ferris et al., 2001; Hirsh, Northrop, \& Schmidt, 1986; Vinchur, Shippmann, Switzer, \& Roth 1998), we did not find the usual positive and significant relationship between GMA and job performance.

Although previous studies (Côté \& Miners, 2006; Elfenbein \& Ambady, 2002; Law et al., 2004) have reported significant correlations between measures of $\mathrm{El}$ and job performance, none of these studies tested whether ability El or skill El explains additional variance in overall job performance after GMA and personality are controlled. We conducted a hierarchical regression analysis to analyze this issue, and the results are reported in Table 4. As Table 4 shows, and consistent with Hypothesis 5, emotional reasoning skills (i.e., skill El) explained a significant additional proportion of variance in overall job performance beyond GMA and personality (i.e., the Big Five). The standardized beta weight was $\beta=-.21(p<.05)$. Separate analyses were also conducted for the supervisor and the peer performance ratings. The subordinate ratings referred to only 16 targets. The standardized beta weight in the supervisor group was $\beta=-.18(n=51)$, and in the peer group $\beta=-.21(n=66)$. However, the $\beta$-weights were not significant, possibly because of the smaller sample sizes in these subgroups.

\section{Discussion}

In two studies, construct and criterion-related validity of the TEMINT (Schmidt-Atzert \& Bühner, 2002), a measure for emotional reasoning skills, was examined. As hypothesized in Study 1, TEMINT was related significantly to the DANVA(Baum \& Nowicki, 1998), an established measure of emotion recognition ability. TEMINT also was significantly related to a measure of the motivation to perceive and understand emotions in others; namely, a global self-rating measure of emotional empathy (Mehrabian \& Epstein, 1972). These 


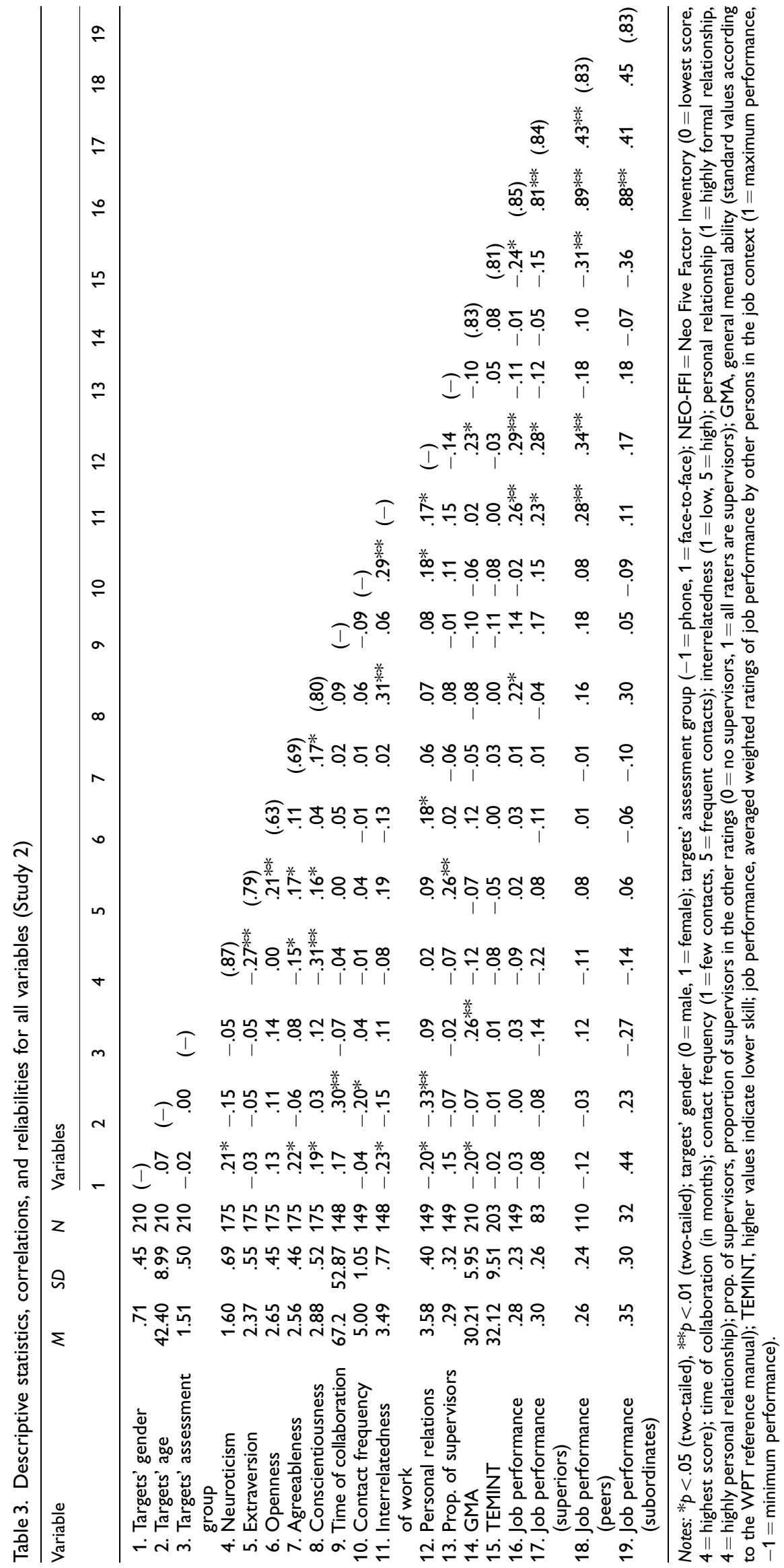


Table 4. Hierarchical regression of overall job performance ratings on emotional skill (TEMINT), GMA, personality, and controls (Study 2)

\begin{tabular}{|c|c|c|c|c|}
\hline & \multirow[t]{2}{*}{ Predictors } & \multicolumn{3}{|c|}{ Overall job performance ratings } \\
\hline & & $\begin{array}{l}\text { All raters } \\
(N=84 \text { targets }) \\
\text { Std. betas }\end{array}$ & $\begin{array}{l}\text { Superiors } \\
(N=51 \text { targets }) \\
\text { Std. betas }\end{array}$ & $\begin{array}{l}\text { Peers } \\
(N=66 \text { targets }) \\
\text { Std. betas }\end{array}$ \\
\hline \multirow[t]{9}{*}{ Step 1} & Targets' gender & -.15 & .08 & $-.24^{+}$ \\
\hline & Targets' age & .02 & -.08 & .04 \\
\hline & Targets' assessment group & .06 & -.24 & .19 \\
\hline & General mental ability (GMA) & .01 & .07 & .04 \\
\hline & Neuroticism & .05 & $-.33^{+}$ & .04 \\
\hline & Extraversion & -.17 & .02 & .09 \\
\hline & Openness to experience & -.11 & -.16 & -.13 \\
\hline & Agreeableness & .09 & -.23 & .04 \\
\hline & Conscientiousness & $.21^{+}$ & -.14 & .15 \\
\hline \multirow[t]{5}{*}{ Step 2} & Time of vollaboration & .21 & .23 & $.21^{+}$ \\
\hline & Contact frequency & $-.36 * * *$ & -.25 & -.15 \\
\hline & Interrelatedness of work & $.44 * * *$ & $.40^{*}$ & .17 \\
\hline & Personal relations & $.36 * * *$ & $.28^{+}$ & $.35 * *$ \\
\hline & Prop. of supervisors & -.14 & & \\
\hline \multirow[t]{2}{*}{ Step 3} & Emotional skill (TEMINT) & $-.21 *$ & -.18 & -.21 \\
\hline & $\Delta R^{2}$ emotional skill (TEMINT) & $.04^{*}$ & .02 & .03 \\
\hline$R^{2}$ overall & & $.53 * * *$ & $.48^{*}$ & $.38 *$ \\
\hline
\end{tabular}

Notes: ${ }^{+} p<.05$ (one-tailed), ${ }^{*} p<.05$ (two-tailed), ${ }^{* *} p<.01$ (two-tailed), ${ }^{* * *} p<.005$ (two-tailed); ratings refer to 84 target persons rated by a total of 217 raters (62 superiors, 121 peers, 19 subordinates, and 15 others), weighted by importance; targets' Gender $(0=$ male, $1=$ female); targets' assessment group $(-1=$ phone, $1=$ face-to-face), personality variables in Step 1 are based on self-ratings in the NEO Five Factor Inventory; contact frequency and interrelatedness, higher values indicate more frequent contacts and higher degree of interrelatedness; low values for personal relationship indicate formal relationship, high values indicate personal relationship; prop. of supervisors, proportion of supervisors in the other ratings; GMA, general mental ability, higher values indicate better performance; TEMINT, higher values indicate lower skill. TEMINT, Test of Emotional Intelligence.

findings concerning construct validity confirm that TEMINT assesses the emotional reasoning skills to correctly appraise and understand emotions evoked in others by situations. In this section, we discuss some of the contributions and implications of this research.

\subsection{Contributions and implications of the research}

TEMINT was significantly related to three measures of successful social functioning (i.e., social astuteness, interpersonal influence, and apparent sincerity) assessed by peers, even after controlling for the personality traits and occupational environment characteristics. These results extend prior research on the association between El and social effectiveness (e.g., Brackett et al., 2006; Lopes et al., 2004). Additionally, the results build on and support contemporary research on political skill, and its relationship with social and emotional competencies, which have been argued to be significant, yet only modest in magnitude (e.g., Ferris et al., 2005; Ferris et al., 2005).

Study 2 was a longitudinal, predictive validation study of TEMINT's role in explaining overall job performance ratings variance. Results demonstrated that the TEMINT measure explained additional variance in overall job performance ratings beyond GMA, personality traits, demographics, and relationship controls. In sum, emotional reasoning skills appear to enhance successful social functioning, and improve overall job performance beyond cognitive ability and personality.

The effect sizes of the uncorrected criterion-related correlations, with different data sources and different assessments modality of TEMINT, were in the range between $r=-.26$ (overall job performance) in a predictive design and $r=-.37$ (apparent sincerity) in a concurrent design. According to the meta-analysis of Schmidt and Hunter (1998), GMA and conscientiousness are the strongest correlates of job performance. In this meta-analysis, the mean observed uncorrected criterion-related correlation of intelligence and job performance is $r=.28$ (F. Schmidt, personal communication, November 25, 2003).

Barrick, Mount, and Judge (2001) conducted a metaanalysis of the meta-analyses regarding the relationship between the five-factor model personality traits and overall job performance, and found that conscientiousness was the strongest personality predictor. In these meta-analyses, the mean observed uncorrected criterion-related correlation between conscientiousness and job performance was $r=.12$ (Barrick et al., 2001). Thus, the criterion-related validity of TEMINT falls within the range of the best predictors of overall job performance.

The correlation between DANVA and TEMINT $(r=.26$, cf., Table 1) falls within the range of correlations among subscales of the MSCEIT reported in a 
validation study by Mayer et al. (2003), which ranged between $r=.17$ and .28 . Additionally, when we examine this correlation after reliability corrections (Hunter \& Schmidt, 2004), it is $\rho=.50$, which provides strong support for the construct validity of the TEMINT scale as a measure of the emotional reasoning skills.

Inconsistent results were found concerning the relationship between TEMINT and openness to experience in the two studies. In Study 1, previous findings by Schmidt-Atzert and Bühner (2002) were replicated concerning the significant association between the two scales. In Study 2, the relationship was not significantly different from zero. Further research is needed to identify potential moderating conditions. One explanation for the zero correlation in Study 2 may be a variance restriction issue (Hunter \& Schmidt, 2004). Although the variance of openness to experience in Study 1 was $S D=.56$, it was only $S D=.45$ in Study 2 , which represents a $24 \%$ reduction. Because the expected true score correlation of openness to experience and TEMINT is substantial but small, such strong variance restriction can demonstrate a large impact.

In line with some previous research (Ferris et al., 2001; Hirsh et al., 1986; Vinchur et al., 1998), we did not find a significant positive relationship between GMA and job performance ratings. There are several possible explanations for the overall pattern of findings in our study concerning the relationship of GMA with job performance ratings. Simple sampling error also cannot be excluded as a possible explanation. One should take note that the overall level of intelligence was high in the current sample; only the upper $17 \%$ of the American population score is within this range (Wonderlic, 2002). Thus, a ceiling effect might have reduced variance in the GMA scores, and such restriction in range thereby could have reduced the effectiveness of GMA as a predictor of job performance ratings.

Another potential explanation for the lack of a relationship between GMA and job performance in our investigation could be the composition of our measure of job performance, which was comprised of two items that assessed adaptive performance, and one each that measured job dedication and interpersonal facilitation. Thus, two-thirds of our job performance measure reflected types of performance (i.e., adaptive and contextual) that researchers have found to be unrelated to GMA (e.g., Chan \& Schmitt, 2002; Van Scotter \& Motowidlo, 1996), more weakly related to GMA than task performance (e.g., O'Connell, Hartman, McDaniel, Grubb, \& Lawrence, 2007; LePine \& Van Dyne, 2001), or that exhibit personality as stronger predictors than GMA (e.g., Pulakos, Schmitt, Dorsey, Arad, Hedge, \& Borman, 2002).

In sum, overall, this research found encouraging evidence for TEMINT as a valid measure for emotional reasoning skills, supporting Amelang and Steinmayr's
(2006) earlier comments about this scale. Given its demonstrated construct and criterion-related validity, we conclude that it represents a useful measure that researchers can use to further our understanding of El. This investigation demonstrated that knowledge about the association between situations and emotions indeed represents a very helpful way to infer the actual emotional states of others, even when target persons do not display their emotions. Thus, the present investigation gives rise to new ways of successfully training emotional micro-skills (Hayes, 2002).

\subsection{Limitations of the current research}

We acknowledge several limitations of the present research. Note that whereas the correlations found in support of Hypotheses 1-3 were in the expected directions and significant, the evidence is only modest. For a starting point, these correlations are satisficing, but of course not optimal. Because measurement errors and other artifacts can easily attenuate substantial relationships, future research is needed to replicate the results of this research. Another limitation arises from the fact that no parallel-test reliabilities of TEMINT are presently available and that the test-retest reliability is based on only a small sample.

In addition, we do not know anything about how much this measure is potentially sensitive to response distortion. At the moment, our findings are limited to cooperative test-takers. However, response distortion may be a concern in high-stakes testing (Tippins, Beaty, Drasgow, Gibson, Pearlman, Segall, \& Shepherd, 2006). Many practitioners highly value El, which may raise testtakers' motives to present themselves as persons with high El. Because TEMINT is an ability-based measure, individuals should not be able to present themselves as more skilled than they really are. However, this remains an issue for future empirical investigation.

Another potential limitation is that archival performance data from human resources records were not available for examination and analyses in Study 2. Thus, the possibility exists that our criterion (i.e., job performance) is not reflective of the performance evaluations given by the organization. Future research needs to address this concern.

\subsection{Directions for future research}

As a scale that focuses on the emotional reasoning component of El, TEMINT taps primarily into branch 3 (i.e., emotional understanding) of the Mayer et al. (2002, $2003,2004)$ integrative-model of El. To precisely locate TEMINT in the nomological network of El, future research should investigate convergent and discriminant validity of TEMINT, through, for example, directly 
examining its relationship with the various branches of MSCEIT, as well as other El measures. Further, because TEMINT measures emotional reasoning skill, it should be possible to change TEMINT scores substantially by implementing emotional competencies training. Therefore, future research should consider designing, implementing, and evaluating training efforts aimed at emotional skill building.

Previous research demonstrated that emotion recognition ability measured by DANVA predicted leadership performance (Rubin, Munz, \& Bommer, 2005). In that study, 480 subordinates completed leadership measures on 145 managers. DANVA predicted transformational leadership behavior rated by subordinates beyond managers' positive and negative affectivity, agreeableness, and extraversion. Thus, future research may consider examining relationships between TEMINT and other important work outcomes, such as leadership performance and team effectiveness.

\section{Conclusion}

This two-study investigation provided further evidence regarding the value of TEMINT as a performance-based, specific-ability measure of El. This measure of emotional reasoning skills appears to relate to emotional perception ability, motivation to appraise and understand emotions, successful social functioning, and predict overall job performance beyond GMA and personality traits. Thus, TEMINT demonstrated encouraging evidence of construct validity, and exhibited incremental validity beyond personality traits and GMA in criterion measures of social interaction and overall job performance ratings. We hope the results of this research stimulate further scientific inquiry into the nature and importance of emotional reasoning skills, as well as other emotional competencies entailed by El, such that richer information is made available for the field of El to move further forward.

\section{References}

Ackerman, P.L. and Heggestad, E.D. (1997) Intelligence, Personality, and Interests: Evidence for overlapping traits. Psychological Bulletin, 121, 219-245.

Aiken, L.S. and West, S.G. (1991) Multiple Regression: Testing and interpreting interactions. Newbury Park, CA: Sage Publications.

Amelang, M. and Steinmayr, R. (2006) Is There a Validity Increment for Tests of Emotional Intelligence in Explaining the Variance of Performance Criteria? Intelligence, 34, 459468.
Bar-On, R. (2000) Emotional and Social Intelligence: Insights from the emotional quotient. In: Bar-On, R. and Parker, J.D.A. (eds), The Handbook of Emotional Intelligence: Theory, development, assessment, and application at home, school, and in the workplace. San Francsico: Jossey-Bass, pp. 363-388.

Barrick, M.R., Mount, M.K. and Judge, T.A. (2001) Personality and Job Performance at the Beginning of the New Millennium: What do we know and where do we go next? International Journal of Selection and Assessment, 9, 9-30.

Baum, K. and Nowicki, S. (1998) Perception of Emotion: Measuring decoding accuracy of adult prosodic cues varying in intensity. Journal of Nonverbal Behavior, 22, 89-109.

Bergmann, C. and Eder, F. (1992) Allgemeiner Interessen-Struktur-Test - Umwelt-Struktur-Test Testmappe [Test of general structure of interests - Environment-structure-test manual]. Weinheim, FRG: Beltz.

Blickle, G., Meurs, J.A., Schneider, P.B., Kramer, J., Zettler, I., Maschler, J., Noethen, D. and Ferris, G.R. (2008) Personality, Political Skill, and Job Performance. Journal of Vocational Behavior, 72, 377-387.

Borkenau, P. and Ostendorf, F. (1993) NEO-Fünf-FaktorenInventar (NEO-FFI) nach Costa und McCrae. Göttingen, FRG: Hogrefe.

Bowen, C., Swim, J.K. and Jacobs, R.R. (2000) Evaluating Gender Biases on Actual Job Performance or Real People: A meta-analysis. Journal of Applied Social Psychology, 33, 648-665.

Brackett, M.A. and Mayer, J.D. (2003) Convergent, Discriminant, and Incremental validity of Competing Measures of Emotional Intelligence. Personality and Social Psychology Bulletin, 29, 1147-1158.

Brackett, M.A., Rivers, S.E., Shiffman, S., Lerneer, N. and Salovey, P. (2006) Relating Emotional Abilities to Social Functioning: A comparison of self-report and performance measures of emotional intelligence. Journal of Personality and Social Psychology, 91, 780-795.

Camras, L.A. and Allison, K. (1989) Children's and Adults' Beliefs About Emotion Elicitation. Motivation and Emotion, 13, 53-70.

Caruso, D.R. and Salovey, P. (2004) The Emotionally Intelligent Manager. San Francisco, CA: Jossey-Bass.

Chan, D. and Schmitt, N. (2002) Situational Judgment and Performance. Human Performance, 15, 233-254.

Ciarrochi, J.V., Chan, A.Y.C. and Caputi, P. (2000) A Critical Evaluation of the Emotional Intelligence Construct. Personality and Individual Differences, 28, 539-561.

Clore, G.L., Ortony, A. and Foss, M.A. (1987) The Psychological Foundations of the Affective Lexicon. Journal of Personality and Social Psychology, 53, 751-766.

Conway, J.M. (1999) Distinguishing Contextual from Task Performance for Managerial Jobs. Journal of Applied Psychology, 84, 3-13.

Costa, P.T. and McCrae, R.R. (1989) NEO-PI/NEO-FFI Manual Supplement. Odessa, FL: Psychological Assessment Resources.

Côté, S. and Miners, C.T.H. (2006) Emotional Intelligence, Cognitive Intelligence, and Job Performance. Administrative Science Quarterly, 51, 1-28.

Daus, C.S. and Ashkanasy, N.M. (2005) The Case for the AbilityBased Model of Emotional Intelligence in Organizational Behavior. Journal of Organizational Behavior, 26, 453-466. 
Davies, M., Stankov, L. and Roberts, R.D. (1998) Emotional Intelligence: In search of an elusive construct. Journal of Personality and Social Psychology, 75, 989-1015.

Davis, M.H. (1983) Measuring Individual Differences in Empathy: Evidence for a multidimensional approach. Journal of Personality and Social Psychology, 44, 113-126.

De Gruijter, D.N.M. (2003) Reliability. In: Fernández-Ballesteros, R. (ed.), Encyclopedia of Psychological Assessment, Vol. 2. London: Sage, pp. 807-812.

Denham, S.A. (1998) Emotional Development in Young Children. New York: Guilford.

Ekman, P. (1972) Universals and Cultural Differences in Facial Expressions of Emotion. In: Cole, J.K. (ed.), Nebraska Symposium on Motivation, 1971. Lincoln, NE: University of Nebraska Press, pp. 207-283.

Ekman, P., Friesen, W.V. and Ancoli, S. (1980) Facial Designs of Emotional Experience. Journal of Personality and Social Psychology, 39, 1125-1134.

Elfenbein, H.A. (2006) Learning in Emotion Judgements: Training and the cross-cultural understanding of facial expressions. Journal of Nonverbal Behavior, 30, 21-36.

Elfenbein, H.A. and Ambady, N. (2002) Predicting Workplace Outcomes from the Ability to Eavesdrop on Feelings. Journal of Applied Psychology, 87, 963-971.

Elfenbein, H.A., Foo, M.D., White, J., Tan, H.H. and Aik, V.C. (2007) Reading Your Counterpart: The benefit of emotion recognition accuracy for effectiveness in negotiation. Journal of Nonverbal Behavior, 31, 205-223.

Elfenbein, H.A., Polzer, J.T. and Ambady, N. (2007) Team Emotion Recognition Accuracy and Team Performance. In: Ashkanasy, N.M., Zerbe, W.J. and Härtel, C.E.J. (eds), Research on Emotions in Organizations, Vol. 3. Amsterdam: Elsevier, Pp. 87-119.

Eslinger, P.J. (1998) Neurological and Neuropsychological Bases of Empathy. European Journal of Neurology, 39, 193-199.

Fernández-Dols, J.M. and Ruiz-Belda, M.A. (1997) Spontaneous Facial Behavior During Intense Emotional Episodes: Artistic truth and optical truth. In: Russel, J.A. and Fernández-Dols, J.M. (eds), The Psychology of Facial Expression. Cambridge: Cambridge University Press, pp. 255-294.

Ferris, G.R., Blickle, G., Schneider, P.B., Kramer, J., Zettler, I., Solga, J., Noethen, D. and Meurs, J.A. (2008) Political Skill Construct and Criterion-Related Validation: A two-study investigation. Journal of Managerial Psychology, 23, 744-771.

Ferris, G.R., Davidson, S.L. and Perrewé, P.L. (2005) Political Skill at Work: Impact on work effectiveness. Mountain View, CA: Davies-Black Publishing.

Ferris, G.R., Judge, T.A., Rowland, K.M. and Fitzgibbons, D.E. (1994) Subordinate Influence and the Performance Evaluation Process: Test of a model. Organizational Behavior and Human Decision Processes, 58, 101-135.

Ferris, G.R., Perrewé, P.L. and Douglas, C. (2002) Social Effectiveness in Organizations: Construct validity and research directions. Journal of Leadership and Organizational Studies, 9, 49-63.

Ferris, G.R., Treadway, D.C., Kolodinsky, R.W., Hochwarter, W.A., Kacmar, C.J., Douglas, C. and Frink, D.D. (2005) Development and Validation of the Political Skill Inventory. Journal of Management, 31, 126-152.
Ferris, G.R., Witt, L.A. and Hochwarter, W.A. (2001) Interaction of Social Skill and General Mental Ability on Job Performance and Salary. Journal of Applied Psychology, 86, 1075-1082.

Fridlund, A.J. (1991) Sociality of Solitary Smiling: Potentiation by an implicit audience. Journal of Personality and Social Psychology, 60, 229-240.

Goffman, E. (1959) The Presentation of Self in Everyday Life. New York: Bantam Books.

Goldberg, L.R. (1993) The Structure of Phenotypic Personality Traits. American Psychologist, 48, 26-34.

Goleman, D. (1995) Emotional Intelligence: Why it can matter more than IQ. New York: Bantam.

Goleman, D. (1998) Working with Emotional Intelligence. New York: Bantam Books.

Harris, M.M. and Schaubroeck, J. (1988) A Meta-Analysis of Self-Supervisor, Self-Peer, and Peer-Supervisor Ratings. Personnel Psychology, 41, 43-62.

Harrison, R. (1986) The Grouping of Affect Terms According to the Situations Which Elicit Them: A test of a cognitive theory of emotion. Journal of Research in Personality, 20, 252-266.

Hayes, J. (2002) Interpersonal Skills at Work. London, GB: Routledge, Taylor \& Francis Group.

Hirsh, H.R., Northrop, L.C. and Schmidt, F.L. (1986) Validity Generalization Results for Law Enforcement Occupations. Personnel Psychology, 39, 399-420.

Hochschild, A.R. (1983) The Managed Heart. Berkeley, CA: University Press.

Holland, J.L. (1997) Making Vocational Choices: A theory of vocational personalities and work environments (3rd edn.). Odessa, FL: Psychological Assessment Resources.

Hunter, J.E. and Schmidt, F.L. (2004) Methods of Meta-Analysis: Correcting error and bias in research findings (2nd edn.). Beverly Hills, CA: Sage Publications.

Innes-Ker, A. and Niedenthal, P.M. (2002) Emotion Concepts and Emotional States in Social Judgment and Categorization. Journal of Personality and Social Psychology, 83, 804-816.

Jörin, S., Stoll, F., Bergmann, S. and Eder, F. (2004) EXPLORIX. Bern, $\mathrm{CH}$ : Huber.

Judge, T.A. and Ferris, G.R. (1993) Social Context of Performance Evaluation Decisions. Academy of Management Journal, 36, 80-105.

Kent, J. and Plomin, R. (1987) Testing Specific Cognitive Abilities by Telephone and Mail. Intelligence, 11, 391-400.

Klein, C., DeRouin, R.E. and Salas, E. (2006) Uncovering Work Place Interpersonal Skills: A review, framework, and research agenda. In: Hodgkinson, G.P. and Ford, J.K. (eds), International Review of Industrial and Organizational Psychology, Vol. 21 (pp. 79-126). Chichester, UK: John Wiley \& Sons.

Kliegel, M., Martin, M. and Jäger, T. (2007) Development and Validation of the Cognitive Telephone Screening Instrument (COGTEL) for the Assessment of Cognitive Function Across Adulthood. The Journal of Psychology, 141, 147-170.

Kraut, R.E. and Johnston, R.E. (1979) Social and Emotional Messages of Smiling: An ethological approach. Journal of Personality and Social Psychology, 37, 1539-1553.

Lam, L.T. and Kirby, S.L. (2002) Is Emotional Intelligence an Advantage? An Exploration of the Impact of Emotional and General Intelligence on Individual Performance. Journal of Social Psychology, 142, 133-143. 
Lane, R.D., Quinlan, D.M., Schwartz, G.E., Walker, P.A. and Zeitlin, S.B. (1990) The Levels of Emotional Awareness Scale: A cognitive-developmental measure of emotion. Journal of Personality Assessment, 55, 124-134.

Law, K.S., Wong, C.-S. and Song, L.J. (2004) The Construct and Criterion Validity of Emotional Intelligence and its Potential Utility for Management Studies. Journal of Applied Psychology, 89, 483-496.

Lazarus, R.S. (1991) Emotion and Adaptation. New York: Oxford University Press.

Legree, P.J., Fischl, M.A., Gade, P.A. and Wilson, M. (1998) Testing Word Knowledge by Telephone to Estimate General Cognitive Aptitude Using an Adaptive Test. Intelligence, 26, 91-98.

LePine, J.A. and Van Dyne, L. (2001) Voice and Cooperative Behavior as Contrasting Forms of Contextual Performance: Evidence of differential relationships with big five personality characteristics and cognitive ability. Journal of Applied Psychology, 86, 326-336.

Liu, Y. (2006). The Antecedents and Consequences of Emotion Regulation at Work. Unpublished doctoral dissertation, Department of Management, College of Business, Florida State University, Tallahassee, FL.

Locke, E.A. (2005) Why Emotional Intelligence is an Invalid Concept. Journal of Organizational Behavior, 26, 425-431.

Lopes, P.N., Brackett, M.A., Nezlek, J.B., Schütz, A., Sellin, I. and Salovey, P. (2004) Emotional Intelligence and Social Interaction. Personality and Social Psychology Bulletin, 30, 1018-1034.

Lopes, P.N., Salovey, P. and Straus, R. (2003) Emotional Intelligence, Personality, and the Perceived Quality of Social Relationships. Personality and Individual Differences, 35, 641-658.

Matsumoto, D., LeRoux, J.A., Wilson-Cohn, C., Raroque, J., Kooken, K., Ekman, P., Yrizarry, N., Loewinger, S., Uchida, H., Yee, A., Amo, L. and Goh, A. (2000) A New Test to Measure Emotion Recognition Ability: Matsumoto and Ekman's Japanese and Caucasian Brief Affect Recognition Test (JACBART). Journal of Nonverbal Behavior, 24, 179-209.

Mayer, D.M., Roberts, R.D. and Barsade, S.G. (2008) Human Abilities: Emotional intelligence. Annual Review of Psychology, 59, 507-536.

Mayer, J.D. and Salovey, P. (1993) The Intelligence of Emotional Intelligence. Intelligence, 17, 433-442.

Mayer, J.D. and Salovey, P. (1997) What is Emotional Intelligence? In: Salovey, P. and Sluyter, D. (eds), Emotional Development and Emotional Intelligence: Implications for educators. New York: Basic Books, Pp. 3-31.

Mayer, J.D., Salovey, P. and Caruso, D. (2000) Models of Emotional Intelligence. In: Sternberg, R.J. (ed), Handbook of Intelligence ( $2^{\text {nd }}$ edn). New York: Cambridge University Press, Pp. 396-420.

Mayer, J.D., Salovey, P. and Caruso, D.R. (2002) Mayer-SaloveyCaruso Emotional Intelligence Test (MSCEIT) User's Manual. Toronto, Canada: MHS Publishers.

Mayer, J.D., Salovey, P. and Caruso, D.R. (2004) Emotional Intelligence: Theory, findings, implications. Psychological Inquiry, 15, 197-215.

Mayer, J.D., Salovey, P., Caruso, D.R. and Sitarenios, G. (2003) Measuring Emotional Intelligence with the MSCEIT V2.0. Emotion, 3, 97-105.
McCrae, R.R. (1996) Social Consequences of Experiential Openness. Psychological Bulletin, 120, 323-337.

Mehrabian, A. and Epstein, N.A. (1972) A Measure of Emotional Empathy. Journal of Personality, 40, 525-543.

Nowicki, S. and Carton, J. (1993) The Measurement of Emotional Intensity from Facial Expressions. Journal of Social Psychology, 133, 749-750.

Nowicki, S. and Duke, M.P. (1994) Individual Differences in the Nonverbal Communication of Affect: The diagnostic analysis of nonverbal accuracy scale. Journal of Nonverbal Behavior, 18, 9-35.

Nowicki, S. and Duke, M.P. (2001) Nonverbal Reciprocity: The diagnostic analysis of nonverbal accuracy (ANVA). In: Hall, J.A. and Bernieri, F.J. (eds), Interpersonal Sensitivity: Theory and measurement. Mahwah, NJ: Lawrence Erlbaum, Pp. 183198.

O'Connel, M.S., Hartman, N.S., McDaniel, M.A., Grubb III, W.L. and Lawrence, A. (2007) Incremental Validity of Situational Judgment Tests for Task and Contextual Job Performance. International Journal of Selection and Assessment, 15, 19-29.

Plutchik, R. (1980) A General Psychoevolutionary Theory of Emotion. In: Plutchik, R. and Kellerman, H. (eds), Emotion: Theory, research, and experience, Vol. 1. San Diego, CA: Academic Press, pp. 3-33.

Prati, L.M., Douglas, C., Ferris, G.R., Ammeter, A.P. and Buckley, M.R. (2003) Emotional Intelligence, Leadership, Effectiveness, and Team Outcomes. The International Journal of Organizational Analysis, 11, 21-40.

Pulakos, E.D., Schmitt, N., Dorsey, D.W., Arad, S., Hedge, J.W. and Borman, W.C. (2002) Predicting Adaptive Performance: Further tests of a model of adaptability. Human Performance, 15, 299-323.

Roberts, R.D., Zeidner, M. and Matthews, G. (2001) Does Emotional Intelligence Meet Traditional Standards for an Intelligence? Some New Data and Conclusions. Emotion, 1, 196-231.

Rode, J.C., Mooney, C.H., Artaud-Day, M.L., Near, J.P., Baldwin, T.T., Rubin, R.S. and Bommer, W.H. (2005) Emotional Intelligence and Individual Performance: Evidence for direct and moderated effects. Journal of Organizational Behavior, 28, 399-421.

Rogers, E.M. (1982) Information Exchange and Technological Innovation. In: Sahal, D. (ed), The Transfer and Utilization of Technical Knowledge. Lexington, MA: Lexington Books, Pp. 105-123.

Rosenthal, R., Hall, J., DiMatteo, M.R., Rogers, P.L. and Archer, D. (1979) Sensitivity to Nonverbal Communication: The PONS test. Baltimore: John Hopkins University Press.

Rubin, R.S., Munz, D.C. and Bommer, W.H. (2005) Leading from Within: The effects of emotion recognition and personality on transformational leadership behavior. Academy of Management Journal, 48, 845-858.

Saarni, C. (1999) The Development of Emotional Competence. New York: Guilford Press.

Scherer, K. (1984) On the Nature and Function of Emotion: A component process approach. In: Scherer, K. and Ekman, P. (eds), Approaches to Emotion. Hillsdale, NJ: Erlbaum, Pp. 293-318. 
Schmidt, F.L. and Hunter, J.E. (1998) The Validity and Utility of Selection Methods in Personnel Psychology: Practical and theoretical implications of 85 years of research findings. Psychological Bulletin, 124, 437-454.

Schmidt-Atzert, L. and Bühner, M. (2002). Development of a Performance Measure of Emotional Intelligence. Paper presented at the 43rd congress of the German Psychological Society. Humboldt-Universität, Berlin, Germany.

Schmitt, N., Cortina, J.M., Ingerick, M.J. and Wiechmann, D. (2003) Personnel Selection and Employee Performance. In: Borman, W.C., Ilgen, D.R. and Klimoski, R.J. (eds), Handbook of Psychology, Vol. 12: Industrial and organizational psychology. Hoboken, NJ: Wiley, pp. 77-105.

Smith, C.A. and Lazarus, R.S. (1993) Appraisal Components, Core Relational Themes, and Emotions. Cognition and Emotion, 7, 233-269.

Spector, P.E. (2001) Research Methods for Data Collection and Data Analysis. In: Anderson, N., Ones, D.S., Sinangil, H.K. and Viswesvaran, C. (eds), Handbook of Industrial, Work, and Organizational Psychology, Vol. 1: Personnel psychology. London, UK: Sage Publications, pp. 10-26.

Tippins, N.T., Beaty, J., Drasgow, F., Gibson, W.M., Pearlman, K., Segall, D.O. and Shepherd, W. (2006) Unproctored Internet Testing in Employment Settings. Personnel Psychology, 59, 189-225.

Van Rooy, D.L. and Viswesvaran, C. (2004) Emotional Intelligence: A meta-analytic investigation of predictive validity and nomological net. Journal of Vocational Behavior, 65, 71-95.
Van Scotter, J.R. and Motowidlo, S.J. (1996) Interpersonal Facilitation and Job Dedication as Separate Facets of Contextual Performance. Journal of Applied Psychology, 81, 525-531.

Vinchur, A.J., Shippmann, J.S., Switzer, F.S. and Roth, P.L. (1998) A Meta-Analytic Review of Predictors of Job Performance for Salespeople. Journal of Applied Psychology, 83, 586-597.

Viswesvaran, C., Schmidt, F.L. and Ones, D.S. (2005) Is There a General Factor in Ratings of Job Performance? A MetaAnalytic Framework for Disentangling Substantive and Error Influence. Journal of Applied Psychology, 90, 108-131.

Wageman, R. (2001) The Meaning of Interdependence. In Turner, M.E. (ed.), Groups at Work: Theory and research. Mahwah, NJ: Lawrence Erlbaum, pp. 197-217.

Waldman, D.A. and Avolio, B.J. (1986) A Meta-Analysis of Age Differences in Job Performance. Journal of Applied Psychology, 71, 33-38.

Weiner, B. (1985) An Attributional Theory of Achievement Motivation and Emotion. New York: Springer-Verlag.

Weiss, H.M. and Cropanzano, R. (1996) Affective Events Theory: A theoretical discussion of the structure, causes and consequences of affective experiences at work. In: Staw, B.M. and Cummings, L.L. (eds), Research in Organizational Behavior, Vol. 18. Greenwich, CT: JAI, PP. 1-74.

Wonderlic Inc. (1996) Wonderlic Personal Test (WPT - German Version). Libertyville, IL: Wonderlic Personnel Test Inc.

Wonderlic Inc. (2002) Wonderlic Personnel Test \& Scholastic Level Exam: User's manual. Libertyville, IL: Wonderlic. 
Copyright of International Journal of Selection \& Assessment is the property of Blackwell Publishing Limited and its content may not be copied or emailed to multiple sites or posted to a listserv without the copyright holder's express written permission. However, users may print, download, or email articles for individual use. 